\title{
ELECCIONES AUTONÓMICAS GALLEGAS 2005: EL FINAL DE UN RÉGIMEN
}

ÁLVARO XOSÉ LÓPEZ MIRA 


\section{SUMARIO}

1. Introducción: antecedentes. 2. Algunos elementos del sistema ELECTORAL. 3. LOS RESULTADOS. BREVE ANÁLISIS. 


\title{
ELECCIONES AUTONÓMICAS GALLEGAS 2005: EL FINAL DE UN RÉGIMEN
}

\author{
POR \\ ÁLVARO XOSÉ LÓPEZ MIRA \\ Profesor Titular de Ciencia Política y de la Administración \\ Universidad de Vigo
}

\section{INTRODUCCIÓN: ANTECEDENTES}

Comenzamos a escribir esta crónica con los resultados escrutados al 100,0 por ciento (página web oficial de la Xunta de Galicia) en los cuatro distritos gallegos. Paradójicamente, ignorábamos cuál sería la composición final del Parlamento de Galicia porque los procesos electorales de nuestra Comunidad Autónoma constan, inconcebiblemente, de dos actos separados por un intervalo aproximado de una semana; no porque nuestro sistema electoral prevea una doble vuelta, sino porque cerca del 12 por ciento ${ }^{1}$ del censo electoral gallego está formado por los denominados "españoles residentes ausentes" que gozan de la condición política de gallegos (el coloquialmente conocido como censo emigrante), lo que implica una peculiaridad tan extraordinaria que ha estado a punto de suponer que el rumbo político de Galicia en los próximos cuatro años estuviese determinado por ciudadanos que nunca han estado en esta tierra; finalmente, no han modificado la distribución de escaños.

Al margen de esta circunstancia, sobre la que volveremos, estos comicios marcaron el declive de una fuerza política y un líder que parecí-

${ }^{1}$ En la circunscripción de Ourense sería, nada menos, que del 19 por ciento. 
an imbatibles después de dieciséis años y cuatro legislaturas gobernando con mayoría absoluta la Comunidad Autónoma. Numerosos síntomas permitían augurarlo, incluidas todas las encuestas relevantes realizadas $^{2}$; por poner un solo caso, el estudio n. ${ }^{\circ} 2.603$ del $\mathrm{CIS}$ de abril-mayo daba las siguientes estimaciones en porcentaje sobre voto válido:

PP: $45,6 \%$

PSOE: $32,8 \%$

BNG: $20,6 \%$

La cual, comparada con el resultado final en territorio gallego otorga un considerable nivel de precisión:

PP: $44,9 \%$

PSOE: $32,5 \%$

BNG: $19,6 \%$

Explicar las causas de la permanencia, relativamente cómoda, de un Manuel Fraga envejecido e histriónico al frente de la Xunta superaría los límites permisibles en una crónica electoral, pero sí conviene mencionar en este contexto, al menos, una de ellas; en concreto, el hecho de que la oposición estaba dividida en dos fuerzas políticas que mantenían un pulso más firme entre ellas por ocupar el segundo lugar en la clasificación, con alternativas en ese puesto (los ocho primeros años fue el PSOE; los ocho segundos, los nacionalistas del BNG), que en afrontar que era el Partido Popular el que gozaba de confortables mayorías absolutas en el Parlamento gallego. Los excesos identitarios del BNG y su pasado antisistema que permitía satanizarlo recurrentemente en el presente y un Partido Socialista que presentaba un candidato a la Presidencia de la Xunta distinto en cada convocatoria electoral (Emilio Pérez Touriño es el primero en repetir) y caracterizado por su escasa identificación con la defensa de los intereses de Galicia, por no mencionar las extrañas connivencias del Alcalde de A Coruña, Francisco Vázquez, con el poder autonómico, que dinamitaron con estudiada constancia las posibilidades electorales de su partido, son elementos que pueden ayudar a comprender que la nueva etapa política a la que se asoma Galicia se verá, con seguridad, obligada a romper con no pocas ataduras del pasado; unos y otros, vencedores y vencidos.

2 Cierto que, en casi todas ellas, aproximadamente un 30 por ciento del electorado no manifestaba su intención de voto. 


\section{ALGUNOS ELEMENTOS DEL SISTEMA ELECTORAL}

El sistema electoral autonómico es de todo punto semejante al del Congreso de los Diputados: circunscripciones provinciales, listas cerradas y bloqueadas, fórmula de Hondt, barrera electoral del $5 \%$, representación mínima provincial de diez escaños (40, en conjunto) y 75 escaños totales repartidos del siguiente tenor: 24 A Coruña, 22 Pontevedra, 15 Lugo y 14 Ourense. Los elementos distorsionantes de la proporcionalidad (sobre y subrepresentaciones incluidas) e incluso de la igualdad de voto son también, en buena medida, similares. El coste en votos de cada escaño de los dos distritos más poblados (los de tendencia de voto más progresista desde las primeras elecciones autonómicas de 1981 hasta la actualidad) es, aproximadamente, el doble que en los otros dos. El hecho de que más de la mitad de los escaños del Parlamento se atribuya a los distritos por serlo, deja a la distribución proporcional en función de la población de derecho de cada uno, afectada por serios desequilibrios; así, a Lugo con menos de un tercio de la población de A Coruña, le corresponden 15 escaños y a ésta únicamente 24, y lo mismo acontece con los supuestos de Ourense y Pontevedra.

En cualquier caso, estas reglas de juego, francamente mejorables incluso sin necesidad de tocar las cláusulas estatutarias ${ }^{3}$, fueron aceptadas en su día por todas las fuerzas políticas del arco parlamentario autonómico, a pesar de resultar notoriamente favorables a los intereses políticos de los conservadores, primero, de una UCD que obtenía sus mejores resultados de España en Ourense (con Lugo también muy cerca de este óptimo), y después del Partido Popular. Otras, sin embargo, fueron incorporadas durante los mandatos de Manuel Fraga y, cómo cabe imaginar, bonificaban estos mismos intereses. La primera, una aparentemente mínima modificación de la Ley de elecciones al Parlamento de Galicia que se limitó a incrementar la cláusula de barrera del $3 \%$ al $5 \%$ del voto válido emitido en cada circunscripción, lo que provocó, de modo automático, la desaparición parlamentaria de pequeños partidos de talante progresista que, tradicionalmente, obtenían algún escaño porque rondaban el $4 \%$ de voto en los distritos, una vez más, de Pontevedra y A Coruña (en los otros dos esta barrera resulta indiferente); si a eso se le suman los conocidos efectos de la fórmula de Hondt, sumamente beneficiosos para la fuerza política más votada, se pueden adivinar las razones que indujeron esta modificación legislativa

3 Por ejemplo, incrementando el número de escaños en la Cámara autonómica, reduciendo la cifra mínima inicial de los distritos o incluso modificando la fórmula electoral. 
que, además, fue unilateral y no consensuada (como sería de desear en normativas electorales), y se produjo unos meses antes de las elecciones autonómicas de 1993: recuérdese que Fraga y su partido lograron su primera mayoría absoluta en las de 1989, la cual fue muy ajustada (38 escaños de 75), y aún ello por efectos del sistema electoral, ya que el Partido Popular y sus coaligados lograron unos 54.000 votos menos que las restantes fuerzas políticas que obtuvieron representación parlamentaria.

En relación con la segunda regla alterada en estos años, sería el del exponencial aumento geométrico de votantes gallegos que se genera en el denominado "censo electoral de españoles [o de residentes] ausentes" (C.E.R.A.) a partir, sobre todo, de las elecciones autonómicas de 2001 (celebradas unos meses después de la aprobación de un aparentemente inocente Real Decreto 3425/2000, de 15 de diciembre, sobre inscripción de los españoles en los Registros de Matrícula de las Oficinas Consulares en el extranjero); en estos comicios, el Partido Popular obtuvo en Galicia cifras de voto próximas al 70 por ciento entre los electores de este peculiar censo. No queremos detenernos demasiado en consideraciones sobre una legislación que puede redundar en poner en entredicho la legitimidad de un proceso electoral democrático. En su día defendimos por escrito la necesidad de que la numerosa diáspora gallega tuviese algún tipo de voz o representatividad en los órganos políticos de la Comunidad Autónoma (incluso en algún lugar del programa del partido gobernante en Galicia en los últimos lustros, aparecían tales tesis), por ejemplo, a través de un distrito propio no territorial, como acontece en la Asamblea de la República portuguesa o en las dos cámaras legislativas italianas, o mediante un Defensor del emigrante. No parece preciso resaltar la incongruencia jurídica que supone que estos electores no computen, sin embargo, para decidir cuántos escaños se van a adjudicar a cada circunscripción en función de su población de derecho ${ }^{4}$; y dígase lo mismo para las elecciones locales, ya que en no pocos depauperados municipios rurales más del 30 por ciento de sus votantes residen en el extranjero, y alguna alcaldía se ha visto alterada en virtud de su preferencia política distinta (siempre en idéntica dirección) a la de los avecindados realmente en el concejo; no obstante, tampoco se cuentan para determinar la cifra de concejales según los criterios de la legislación electoral, una vez más, tremendamente contradictorios desde el prisma técnico-jurídico, y no sólo.

4 Resulta ilustrativo comprobar cómo Ourense tiene un censo de 9.000 electores más que Lugo y le corresponde, empero, un escaño menos en el Parlamento gallego. 
La maleabilidad de buena parte de estos sufragios (por no hacer hincapié en las evidentes carencias técnicas que permiten falsear o manipular muchos votos) se ha puesto de manifiesto en estas elecciones autonómicas, en las que ha resultado decisivo el cambio de gobierno en Madrid y el curioso nombramiento de una suerte de embajador de la emigración, el socialista Miguel Cortizo, para contrarrestar el peso institucional de la Xunta de Galicia, especialmente en América. Y tales sucedidos no son exclusivos del caso gallego; recuérdese, a modo de ejemplo (hay más), lo que no hace demasiados años aconteció en Formentera y los tintes escandalosos que rodearon esta cuestión por la relevancia que adquirió el voto emigrante, dado lo ajustado del resultado final y sus consecuencias. Parece imperiosa la necesidad de reformar con urgencia (antes de las próximas elecciones municipales) la legislación electoral, pero sin caer en fáciles demagogias. Las paradojas sobre la cuestión llegan a su extremo, si consideramos el hecho de que decenas de miles de gallegos que residen en otras zonas del Estado (pero no en el extranjero), justamente por ello no pueden votar en las elecciones gallegas; la mayor parte de ellos son emigrantes jóvenes con buena formación y tienen como destinos preferentes Madrid, Barcelona o Canarias; en este último caso, el avecindamiento en el archipiélago resulta casi obligado para obtener tarifas beneficiosas en sus vuelos a la península.

\section{LOS RESULTADOS. BREVE ANÁLISIS}

La irrupción de Fraga en la política interna gallega, acompañada de la reforma legislativa antedicha, propició la reducción de fuerzas políticas con representación parlamentaria en el Pazo do Hórreo a únicamente tres. En la actualidad, esta situación no se ha modificado, por lo que tan sólo proporcionaremos los datos relativos a aquéllas. Téngase en cuenta que el conjunto de las trece candidaturas restantes, ronda la ínfima cifra del 1,5 por ciento de los votos emitidos por los electores gallegos, razón por la que un análisis general como el presente no puede entrar en valoraciones de ese detalle. Veamos, por tanto, los datos:

\begin{tabular}{l|c|c|c}
\hline GALICIA & Votos & Porcentaje & Escaños (75) \\
\hline PP & 756.562 & $45,2 \%$ & 37 \\
\hline PSOE & 555.603 & $33,2 \%$ & 25 \\
\hline BNG & 311.953 & $18,7 \%$ & 13 \\
\hline
\end{tabular}


Desglosaremos, a continuación, los mismos datos en los cuatro distritos:

\begin{tabular}{l|c|c|c}
\hline A CORUÑ & Votos & Porcentaje & Escaños (24) \\
\hline PP & 286.278 & $42,9 \%$ & 11 \\
\hline PSOE & 221.436 & $33,2 \%$ & 8 \\
\hline BNG & 136.696 & $20,5 \%$ & 5 \\
\hline
\end{tabular}

\begin{tabular}{l|c|c|c}
\hline PONTEVEDRA & Votos & Porcentaje & Escaños (22) \\
\hline PP & 238.950 & $44,1 \%$ & 10 \\
\hline PSOE & 182.207 & $33,6 \%$ & 8 \\
\hline BNG & 103.297 & $19,2 \%$ & 4 \\
\hline
\end{tabular}

\begin{tabular}{l|c|c|c}
\hline LUGO & Votos & Porcentaje & Escaños (15) \\
\hline PP & 115.650 & $48,9 \%$ & 8 \\
\hline PSOE & 81.709 & $34,5 \%$ & 5 \\
\hline BNG & 34.349 & $14,5 \%$ & 2 \\
\hline
\end{tabular}

\begin{tabular}{l|c|c|c}
\hline OURENSE & Votos & Porcentaje & Escaños (14) \\
\hline PP & 115.684 & $50,8 \%$ & 8 \\
\hline PSOE & 70.251 & $30,9 \%$ & 4 \\
\hline BNG & 37.141 & $16,3 \%$ & 2 \\
\hline
\end{tabular}

La participación se ha incrementado en cuatro puntos respecto de los anteriores comicios autonómicos, superando levemente el 68 por ciento en el territorio ya que, computando los votantes del C.E.R.A., baja hasta el 64 por ciento. Como es tradicional en Galicia, las provincias más participativas son las menos dinámicas económica y demográficamente ${ }^{5}$, Lugo y Ourense superan el 72 por ciento (sin C.E.R.A.), A Coruña y Pontevedra sobrepasan el 66 por ciento. Son cifras homolo-

${ }^{5}$ Tienen las pirámides de población más envejecidas del Estado y en Ourense las clases pasivas ya superan a las activas. 
gables con la media española que confirman la inconsistencia de la vieja teoría acerca del inveterado abstencionismo de los gallegos (pavoroso nihilismo, lo llegó a denominar Ortega y Gasset) en procesos político-electorales.

El Partido Popular y su líder afrontaban estas elecciones con malos presagios. Rompiendo una vez más su promesa de no volver a presentarse, el candidato con más de ochenta y dos años y un partido dividido en, al menos, dos facciones irreconciliables (unos más fieles a la disciplina central del partido; otros defensores a ultranza de sus feudos territoriales, basados en el poder local, especialmente las Diputaciones provinciales), parecía complicado, pese al adelanto electoral (negado por el Presidente de la Xunta hasta el mismo momento de firmar la disolución anticipada de la Cámara autonómica), y pese a la debilidad mutuamente caníbal de los dos partidos de la oposición de izquierdas (nacionalistas y socialistas), que Manuel Fraga se pudiese aupar hasta su quinta mayoría absoluta. Aunque consiguió remontar en campaña, como ya viene siendo tradición en los populares gallegos, el Partido Popular perdió cuatro escaños (manteniendo resultados en Ourense) y más de seis puntos porcentuales de voto, quedándose a un escaño de la mayoría absoluta, necesaria para formar gobierno en solitario ante la imposibilidad de pactar con otras fuerzas políticas, y a pesar del indudable rendimiento que obtuvo del sistema electoral, con una prima en escaños que superó en cuatro puntos a los sufragios obtenidos.

El Partido Socialista logró unos réditos considerables. No sólo ascendió del tercer al segundo puesto su posición en el arco parlamentario, sino que ha terminado encabezando un gobierno de coalición. Incrementó en ocho su número de escaños y en casi doce puntos porcentuales su cifra de sufragios. En general, se han cumplido las previsiones y expectativas que tenía esta fuerza política antes de iniciarse el proceso electoral, aunque, en realidad, la falta de pulso político de la Xunta en los últimos meses, había propiciado, casi inconscientemente, el comienzo de una pre-campaña que se auguraba como interminable de haberse prolongado, como estaba previsto, hasta finales del otoño de este año. El candidato, Emilio Pérez Touriño, con estos resultados, parece haberse impuesto a la poderosa facción del partido encabezada por el Alcalde coruñés, contraria a todo pacto (algo que era completamente inevitable y que ya se había ensayado en los gobiernos locales desde hacía ocho años) con los nacionalistas gallegos.

Éstos, canalizados políticamente por el peculiar Bloque Nacionalista Galego (formación que agrupa a partidos políticos, colectivos di- 
versos y militantes individuales que sólo lo son del Bloque y por eso se Ilaman «independientes»), perdieron cuatro escaños y casi cuatro puntos porcentuales de voto respecto a 2001. En realidad, ya iniciaron la campaña como si no fueran la segunda formación en el Parlamento autonómico y sus expectativas tuvieron cabal cumplimiento (siguiendo fielmente el guión de la profecía autocumplida). Descendieron un escaño en cada circunscripción, cierto que con poca fortuna en los últimos restos, y fueron casi irrelevantes en el voto emigrante, con poco más del 4 por ciento de estos sufragios, muy polarizados en torno a PP y PSOE. El proceso de relevo en el liderazgo de esta fuerza política resultó bastante traumático y todavía estaba abierto cuando se adelantó la convocatoria; su anterior y carismático líder desde 1985, el catedrático Xosé Manuel Beiras, lanzó a la arena pública sus críticas contra el nuevo, el senador y ex alcalde del municipio ourensano de Allariz, Anxo Quintana, quien realizó la mejor campaña de los tres candidatos $y$, sin embargo, no consiguió que el Bloque alcanzase los resultados que las encuestas le pronosticaban de mantener su cuota de asientos en el Parlamento. En cualquier caso, el anunciado gobierno bipartito, ha situado a Quintana en la Vicepresidencia de la Xunta.

El 52 por ciento de los electores gallegos apostaron por el cambio político. Hubiera resultado un desatino que sus representantes electos no alcanzasen la cifra mágica de los 38 escaños para poder formar gobierno. Los desajustes de nuestro sistema electoral chirriarían en demasía si una cifra diferencial de votos entre los coaligados y el Partido Popular idéntica a los sufragios obtenidos por esta fuerza política en Lugo o en Ourense, en ambos casos transformadas en ocho escaños, resultase insuficiente para propiciar la alternancia democrática en el poder por la que, de forma bastante clara ${ }^{6}$, optaron los votantes gallegos. Con una fórmula electoral de resto mayor o con la de Webster o St. Lagüe, el reparto de escaños adjudicaría 36 escaños al PP, 24 al PSOE y 15 al BNG; con un método proporcional puro todavía tendría menos el PP (35), 25 el PSOE y 15 el BNG. No deja de resultar sorprendente para quien esto escribe que se hayan levantado reputadas voces políticas abogando por una reforma del sistema electoral (a posteriori de los comicios) que ignoran olímpicamente los dictados constitucionales en la materia, por no hablar del implícito entredicho hacia un sistema político parlamentarista que a nadie, con un mínimo de raciocinio, parece ocurrírsele discutir.

6 Con una diferencia de votos a su favor casi idéntica, el Partido Popular obtuvo 41 escaños por 34 de sus adversarios en la legislatura anterior de 2001. 
Un último dato que convendría apuntar es la consolidación de la tendencia, ya manifestada en anteriores comicios (generales, municipales...), de clara superioridad electoral de las dos fuerzas políticas progresistas en las áreas urbanas y periurbanas, que incluyen la práctica totalidad de los municipios costeros, desde A Guarda a Ribadeo, además de las capitales del interior (Lugo, Ourense, Santiago de Compostela) y sus zonas de influencia. El Partido Popular, por su parte, mantiene un considerable peso electoral en la inmensa mayoría de los municipios interiores ${ }^{7}$, especialmente en los más reducidos y en alguno de tamaño medio. De todas formas, desglosar los datos y analizarlos en este nivel de microanálisis de los 315 municipios de Galicia como se merecería, superaría el ámbito espacial que debe respetar esta crónica, por lo que solamente repetiremos que parece que la Galicia social y económicamente más avanzada está marcando unas pautas que pueden ser estructurales en un futuro próximo, a poco que se consolide el nuevo gobierno bipartito.

$Y$, ya para finalizar, no queríamos dejar de señalar que la ajustada mayoría emanada de las urnas, puede hacer que el Parlamento recobre un papel de centralidad en nuestro sistema político (parlamentario, al fin y al cabo) que había sido arrumbado en los últimos años. La imparable tendencia hacia un modelo presidencialista sin los controles propios del mismo, que era tan manifiesta en el caso gallego, podría atemperarse hasta el punto de recuperar unas esencias de participación ciudadana y democrática que se habrían podido creer, sin mirar demasiado hacia atrás en el horizonte político, perdidas para siempre.

7 No coincidentes, necesariamente, con los de las provincias de Lugo y Ourense, contrariamente a cómo suele señalar, de manera simplificada, la literatura sobre el tema. 